\title{
Numerical Investigation of Aerodynamic Properties of Ahmed Body for Different Rear Slanted Surface Configurations
}

\author{
Cafer Kamac1 ${ }^{1 *}$, Kenan Kaya ${ }^{1}$ \\ 1* Istanbul Aydin University, Faculty of Engineering, Department of Mechanical Engineering, İstanbul, Turkey, (ORCID: 0000-0003-1083-2444), \\ caferkamaci@stu.aydin.edu.tr \\ ${ }^{1}$ Istanbul Aydin University, Faculty of Engineering, Department of Mechanical Engineering, İstanbul, Turkey, (ORCID: 0000-0002-6897-4077), \\ kenankaya@aydin.edu.tr
}

(1st International Conference on Applied Engineering and Natural Sciences ICAENS 2021, November 1-3, 2021)

(DOI: $10.31590 /$ ejosat.1005846)

ATIF/REFERENCE: Kamac1, C. \& Kaya, K. (2021). Numerical Investigation of Aerodynamic Properties of Ahmed Body for Different Rear Slanted Surface Configurations. European Journal of Science and Technology, (28), 469-475.

\begin{abstract}
The present study investigates aerodynamic characteristics of the Ahmed Body numerically, in case of that small rectangular flaps are attached to the leading edge of the rear slanted surface with a rear tilt angle of $25^{\circ}$ and $35^{\circ}$. Numerical calculations have been conducted for three-dimensional, turbulent, steady, incompressible flow. Three different flap configurations have been considered: single flap, two flaps and three flaps. The commercial computational fluid dynamics solver ANSYS Fluent is used for the computations. To validate the numerical model, numerical solutions have been conducted with different combinations of turbulence model and wall functions, considering the values of drag coefficient obtained in a previous experimental work which studied slanted surface with flaps attached. Accordingly, k-epsilon Realizable turbulence model with Menter-Lechner wall function estimates the drag coefficient with an error of $8.8 \%$. Results of the numerical calculations have shown that the best performance is obtained for the Ahmed model with $25^{\circ}$ rear slant angle with three flaps mounted on the leading edge of the rear slanted surface, which provides a reduction in drag coefficient by $2.3 \%$, compared to the model without flaps. Mechanisms for drag reduction are found to rely on generating a suction line along the leading edge of the rear slanted surface, which provides attached flow, although it is reversed. As for the $35^{\circ} \mathrm{Ahmed}$ model with flaps, on the other hand, no decrease in the drag coefficient is observed.
\end{abstract}

Keywords: Flap, Passive flow control, Computational fluid dynamics, Turbulent flow, Drag coefficient, Aerodynamics.

\section{Farklı Arka Yüzey Konfigürasyonları İçin Ahmed Gövdesinin Aerodinamik Özelliklerinin Sayısal Olarak İncelenmesi}

$\ddot{O} \mathbf{z}$

Bu çalışmada $25^{\circ}$ ve $35^{\circ}$ 'lik arka eğim açısına sahip Ahmed gövdesinin arka eğimli yüzeyinin hücum kenarı üzerine dikdörtgen kanatlar eklenmiş ve bu geometrik model kullanılarak üç boyutlu, türbülanslı, daimî, sıkıştırılamaz akış için sayısal çözümler yapılmıştır. Tek, iki ve üç kanat olmak üzere üç farklı konfigürasyon göz önüne alınmıştır. Sayısal çözümler ticari hesaplamalı akışkanlar dinamiği çözücüsü ANSYS Fluent kullanılarak yapılmıştır. Sayısal modelin doğrulanması amacıyla, daha önce yapılmış bir deneysel çalışmanın sonuçları referans alınarak farklı türbülans modeli ve duvar fonksiyonu kombinasyonları ile sayısal çözümler yapılmıştır. Buna göre \%8.8'lik hata ile k-epsilon Realizable türbülans modeli ve Menter-Lechner duvar fonksiyonu kombinasyonunun deneysel sonuçlara en yakın sonucu verdiği görülmüştür. Sayısal çözüm sonuçları, en iyi performansın kanatsız modele göre sürükleme katsayısında $2.3 \%$ oranında düşüşün sağlandığı, arka eğim açı1Sı $25^{\circ}$ olan üç kanatlı Ahmed modeli için elde edildiğini göstermiş̧ir. Sürükleme katsayısı düşürme mekanizmalarının, arka yüzeyin hücum kenarı üzerinde bir emiş hattı oluşmasına ve ters yönlü olduğu halde akımın arka yüzeye tutunmasına bağlı olduğu tespit edilmiştir. Buna karşılık, arka eğim açısı $35^{\circ}$ olan kanatlı Ahmed modeli için ise sürükleme katsayısında herhangi bir azalma görülmemiştir.

Anahtar Kelimeler: Kanat, Pasif akış kontrolü, Hesaplamalı akışkanlar dinamiği, Türbülanslı akış, Sürükleme katsayısı, Aerodinamik.

*Corresponding Author: caferkamaci@stu.aydin.edu.tr 


\section{Introduction}

Sixty percent of total energy consumed by a land vehicle cruising with an average speed is used to overcome the drag resistance [1]. For this reason, many scientific studies have been carried out to reduce fuel consumption, improve exhaust emissions and reduce noise in vehicles by improving aerodynamic designs. According to a study conducted in the United States, it has been determined that an improvement in the aerodynamic drag force of vehicles by $12 \%$ will save approximately 12 million $\mathrm{m}^{3}$ of fuel, and 28 million tons less exhaust gas is produced [2].

Most aerodynamic problems are too complex to be solved analytically, and therefore rely on correlations based on empirical data. However, obtaining empirical data is a very expensive and time-consuming way. For this reason, thanks to the fast computers developed owing to recent technological improvements, it has made it possible to perform time-consuming and expensive tests of the design at the last stage, i. e., in wind tunnels, by solving the equations governing a particular physical problem numerically and performing several calculations quickly.

Ahmed body is a simplified model [3] used to understand vehicle aerodynamics in experimental and numerical studies. Siddiqui and Chaab [4] analyzed the SST k-omega turbulence model by mounting an adjustable rectangular flap with angles between $0^{\circ}$ and $25^{\circ}$, on the leading edge of the slanted surface of Ahmed model with a slant angle of $35^{\circ}$, using FLUENT software for Reynolds number of $7.8 \times 10^{5}$. They found that a reduction by $14 \%$ in drag coefficient is obtained at most, for a flap angle of $10^{\circ}$. Delassaux et al. [5] conducted a comparative study using the original Ahmed model with a rear tilt angle of $25^{\circ}$ and SST-based RANS and hybrid turbulence models for the rear slanted surface with rounded edges. As a result, they stated that the flow around the sharp-edged model can be solved more accurately with hybrid models. Hanfeng et al. [6] took two Ahmed models with rear slant angles of $25^{\circ}$ and $35^{\circ}$ as a reference and mounted large and small flaps on the rear slanted surface of the Ahmed model with $25^{\circ}$ rear slant angle, for Reynolds number of $4.29 \times 10^{6}$. They found that the flap added to the side edge of the rear slanted surface weakened the longitudinal eddies and there was a reduction by $21.2 \%$ in the drag coefficient at a flap angle of $80^{\circ}$, and $17.9 \%$ for both large and small flaps at $40^{\circ}$ and $20^{\circ}$ angles. For the $35^{\circ}$ Ahmed model, they observed a reduction by $6 \%$ in drag coefficient at $30^{\circ}$ of the large flaps on the top of the vehicle and at $80^{\circ}$ in the large flap configuration on the side. McNally et al. [7] tried to minimize the pressure difference between the front and rear of the vehicle by applying micro jet arrays to the rear slanted surface of the $25^{\circ}$ Ahmed reference model. Micro-jets applied on the side edges of the slanted surface, the rear upper surface and the rear lower surface detected a slight increase in pressure of $1 \%$ and $7 \%$ at the rear of the vehicle. Tsai et al. [8] examined the flow around a vehicle model similar to the Ahmed model numerically, as they used the k-epsilon and Large Eddy Simulation (LES) turbulence model. Kurec et al. [9] investigated the low and high angles of attack of the rear wing attached to an automobile in their study. They examined how an air brake mounted on different locations affects the stability of the car, and the load distribution on the front and rear axles. According to the data collected in the wind tunnel experiments, they determined how effective the aerodynamic properties are on an automobile braking maneuver. In addition, they showed how the rear wing element of the automobile can be used to increase the drag force along with the downforce that can affect the air flow around the automobile. Han et al. [10] designed a shape memory composite material reinforced with glass fiber and alloy wire and a woven type of smart soft composite and applied it to the rear spoiler of a vehicle at a ratio of $1 / 8$ scale and to determine the aerodynamic performance measures of the vehicle in a wind tunnel at various wind speeds, for different operating conditions and angles of attack. They observed that the drag coefficient increases by approximately $41 \%$ while the downforce increases by $198 \%$ during the operation of the spoiler. Yuan et al. [11] conducted a numerical study for the Ahmed model with a flap added to its rear slanted surface and concluded that the aerodynamic lift force decreases approximately linearly with the angle of inclination of the flap, accompanied by an increase in the drag force. Altaf et al. [12] used several elliptical flaps to reduce the drag coefficient for a simplified truck model. The optimum angle of the elliptical flap is found to be $50^{\circ}$ which yields a reduction of $11 \%$ in drag coefficient. Huminic et al. [13] studied the Ahmed model of $35^{\circ}$ rear tilt angle with a $7^{\circ}$ slope on the lower rear part, so that the rear part resembles a venturi nozzle. There was no difference aerodynamically in the lower front part, however, variation in pressure was observed in the curved front lower part of the vehicle. Mohammadikalakoo et al. [14] moved the air stream on the side walls of the vehicle to the rear parts of the vehicle by means of pipes for Ahmed models of $25^{\circ}, 30^{\circ}$ and $35^{\circ}$ rear slant angle, thus minimizing the pressure difference between the rear and front parts of the vehicle. In the experiments, they obtained a drag reduction of $2-5 \%$ in the different configurations for free stream velocities of 10,20 and $30 \mathrm{~m} / \mathrm{s}$, and they found the best drag reduction as $5.07 \%$ at $30 \mathrm{~m} / \mathrm{s}$ speed with the $35^{\circ}$ Ahmed model. In their numerical study, Buscariolo et al. [15] mounted a diffuser on the rear part of the Ahmed model with rear slant angle of $25^{\circ}$ and $0^{\circ}$, for diffuser angles varying between $0^{\circ}$ and $50^{\circ}$. They obtained maximum compression force with a diffuser angle of $10^{\circ}$ in the $25^{\circ}$ Ahmed model. Kashyap et al. [16] aimed to reduce drag by creating spherical depressions with a diameter of $60 \mathrm{~mm}$ and $90 \mathrm{~mm}$, and they achieved a maximum reduction of $6 \%$ in the drag coefficient with a spherical depression at a vehicle speed of $28 \mathrm{~m} / \mathrm{s}$ and an aspect ratio of 4 . Shadmani et al. [17] used an active flow control method to control the rear slant angle and the flow in the rear slanted section with the help of a plasma actuator in the $25^{\circ} \mathrm{Ahmed}$ model, and the drag force decreased by about $2 \%$ at $20 \mathrm{~m} / \mathrm{s}$ speed. Bayindirli et al. [18] found that $13.38 \%$ of the drag force was caused by friction, while $86.42 \%$ of the drag force was caused by pressure, in a study they conducted on a vehicle model of Ahmed Body model with four different Reynolds numbers. As a passive flow control device added in front of the model, an aerodynamic improvement of $5.37 \%$ was achieved in the calculations conducted for four different Reynolds numbers between 173000 and 346 000. Zafer and Haskaraman [19] carried out numerical computations for two different Ahmed models with slant angles of $25^{\circ}$ and $35^{\circ}$, using realizable k-epsilon turbulence model for $2.8 \times 10^{6}$ Reynolds number under front and side wind conditions. As a result, they determined that the width of the wake region, in which two asymmetrical vortices rotate in the opposite direction with each other in the wake of the vehicle, decreases by $60-70 \%$ due to the lateral wind and the leading wind conditions. Bayındırlı and Çelik [20] investigated the effects on friction force for five different Reynolds numbers with a spoiler model with one or two different sizes added to a vehicle model like Ahmed Body. They achieved aerodynamic improvement of $4.96 \%$ and $5.27 \%$, respectively, for spoilers with different heights. Aider and Beaudoin [21] investigated the Ahmed model while they attached adjustable flaps on each side of the rear slanted surface and the rear vertical base. PIV measurements showed that the best efficiency was 
obtained for flaps mounted on the side edges of the rear slanted surface.

In the present study, effect of a novel passive flow control method on the aerodynamic properties of Ahmed body is investigated numerically, where small flaps are mounted on the leading edge of the rear slanted surface of the original Ahmed model, for $25^{\circ}$ and $35^{\circ}$ rear slant angles.

\section{Material and Method}

\subsection{Model Geometry}

Being a generic model vehicle with a relatively simple geometry and adjustable rear tilt angle, Ahmed model has been employed in many studies on vehicle aerodynamics, allowing to analyze the aerodynamic phenomena around the a vehicle without any geometric complexity of a standard vehicle used in real life [22]. The model geometry and its dimensions are shown in Fig. 1, where length and width of the model is $L=1044 \mathrm{~mm}$, and $W=$ $389 \mathrm{~mm}$, respectively. In the present study, small flaps are mounted to the original Ahmed model in three different configurations (Fig. 2), for slant angles of $25^{\circ}$ and $35^{\circ}$. Width ratio is $w / W=0.2$ for all cases, where $w$ and $W$ are width of the flaps and Ahmed model, respectively.

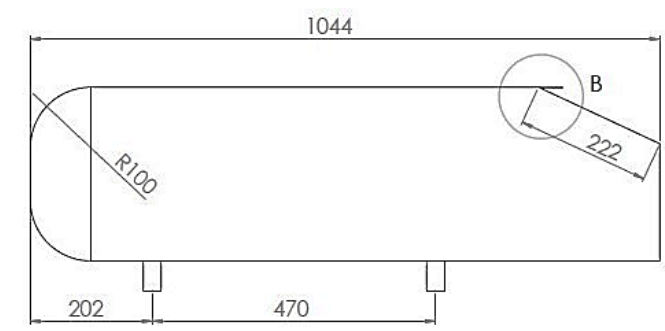

a.

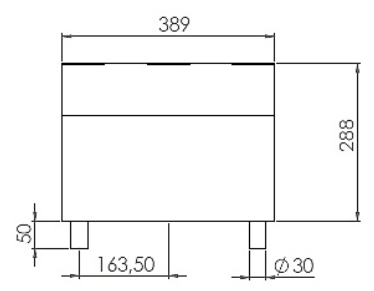

b.

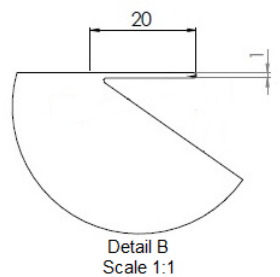

c.
Figure 1. Model geometry used in the present study: a) side view, b) back view, and c) detail view of the flap

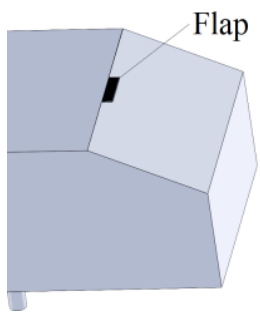

a.

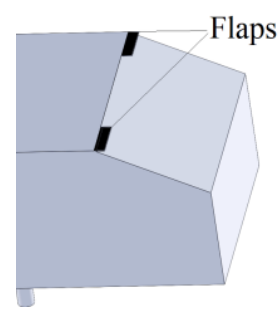

b.

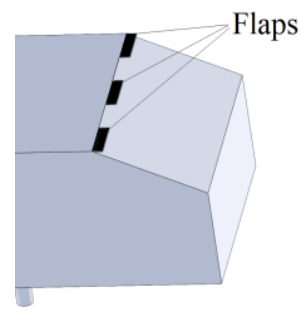

c.
Figure 2. Illustration of passive flow control device for a) single-flap, b) two-flap, and c) three-flap models

\subsection{Numerical Method}

In the present study, numerical calculations are carried out for three-dimensional, incompressible, steady turbulent air flow; using a commercial solver, ANSYS Fluent, version 19.2. Fig. 3 shows the solution domain and boundary conditions employed in the numerical calculations. Velocity inlet boundary condition is assigned to the inlet where a uniform velocity profile is defined with a constant velocity. At the outlet, pressure outlet boundary condition is employed, as static pressure is fixed at zero gauge. Only half of the pyhsical domain is considered in the numerical calculations, assuming that mean flow structures are symmetrical about the longitudinal mid-plane, where symmetry boundary condition is applied. The top and side surfaces of the domain are also defined as boundaries of symmetry, assuming that gradients of all variables are zero. Surfaces of Ahmed body and ground are defined as no-slip walls, where both normal and tangential components of velocity are set as zero.

Dimensions of the numerical solution domain are $6.5 \mathrm{~L} \times 1.5 \mathrm{~L}$ $\mathrm{x} 1.5 L$ (length $\mathrm{x}$ width $\mathrm{x}$ height), where $L$ denotes length of Ahmed body. Distance between the front of the vehicle and the inlet boundary is $0.5 \mathrm{~L}$, while that between the rear of the vehicle and the outlet is $5 L$. The blockage ratio is $3.7 \%$, which is recommended to be less than $7.5 \%$ [23].

Results of a previous experimental study conducted by Aider and Beaudoin [21] are used to validate the numerical model, employing meshes with 2.4, 4.7 and 8.3 million elements. Accordingly, k-epsilon Realizable turbulence model with MenterLechner wall function estimates the drag coefficient with an error of $8.8 \%$. Numerical calculations are repeated for different pairs of turbulence model and wall function by using a mesh with 4.7 million elements, at which mesh independence is achieved. The numerical grid generated for the numerical calculations is shown in Fig. 4, as prismatic elements are located near solid walls, to be able to resolve the boundary layer. Also, a finer mesh is generated in the wake of Ahmed body. It is determined that the turbulence model that yields the closest value of drag coefficient to that of the experimental study is the $k-\varepsilon$ Realizable turbulence model with Menter-Lechner wall function, which are adopted for all the numerical calculations in the present study. The SIMPLE algorithm is used for pressure-velocity coupling. Convective terms in the momentum and turbulence equations are discretized with second-order upwind scheme. Discretization of the pressure term is also achieved using a second-order accurate method. All the numerical calculations converged after 5000 iterations. Solutions are obtained for a free stream velocity of $40 \mathrm{~m} / \mathrm{s}$ at the inlet, which corresponds to a Reynolds number of $\mathrm{Re}=2.6 \times 10^{6}$, based on length of Ahmed body, $L$.

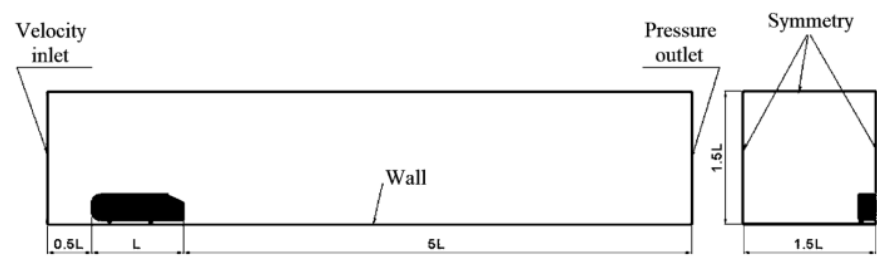

Figure 3. The numerical solution domain and boundary conditions 


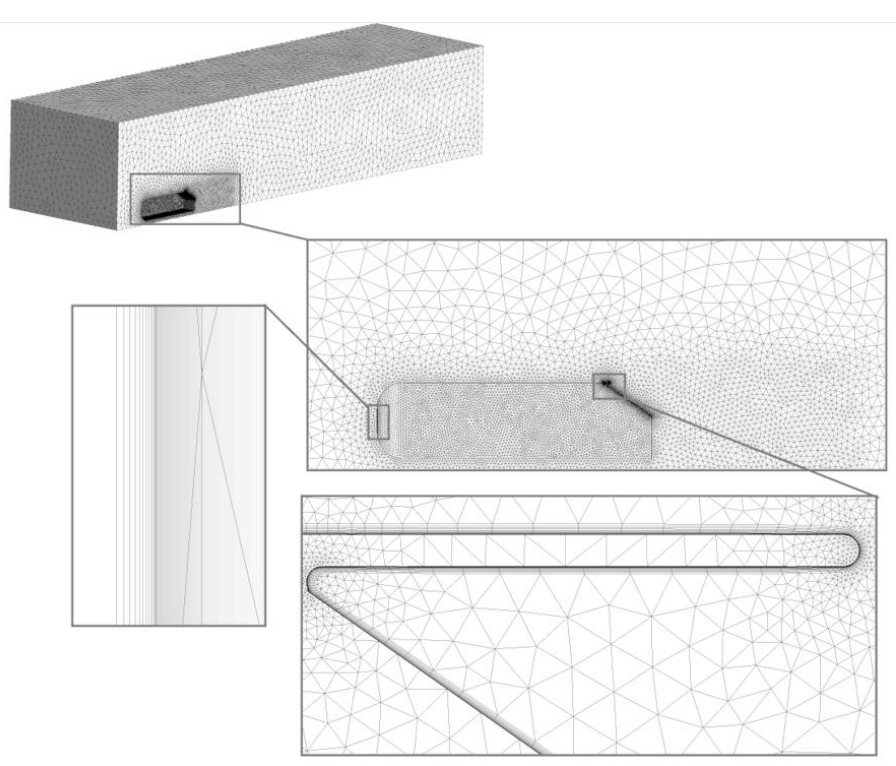

Figure 4. The numerical grid

\section{Results and Discussion}

Values of drag coefficient obtained from the numerical solutions are presented in Table 1, where results related to the reference model without flaps are also given. Accordingly, for $25^{\circ}$ rear slant angle, drag coefficient has the smallest value for the three-flap model, with a reduction of approximately $2.5 \%$. However, for $35^{\circ}$ rear slant angle, variation in drag coefficient can be neglected, while there is a slight increase in drag by less than $1 \%$ for the two- and three-flap models.

Table 1. Calculated values of the drag coefficient

\begin{tabular}{ccc}
\cline { 2 - 3 } Model & \multicolumn{2}{c}{ Drag coefficient, $\boldsymbol{C}_{\boldsymbol{D}}$} \\
\cline { 2 - 3 } & $\mathbf{2 5}^{\mathbf{0}}$ & $\mathbf{3 5}^{\mathbf{0}}$ \\
\hline Reference (no-flap) & 0.353 & 0.343 \\
Single-flap & 0.347 & 0.343 \\
Two-flap & 0.349 & 0.345 \\
Three-flap & 0.344 & 0.345 \\
\hline
\end{tabular}

Figure 5 compares vectors and streamlines on the symmetry plane $(y / W=0)$ for models with $25^{\circ}$ slant angle, indicating that the flow pattern over the slanted surface is distinctive of all cases, whereas the remaining part of the flow pattern is almost identical. Two distinct flow patterns are remarkable: For the no-flap and two-flap models, a secondary vortex exists above the slanted surface (Figs. 5a and 5c); while employing a small flap centered around the midpoint of the leading edge eliminates formation of such a vortex, by preventing direct interaction between highvelocity stream and the reversed flow and allowing the reversed flow to climb along the slanted surface almost up to the leading edge owing to generation of local suction regions below the flaps, for the single- and three-flap models (Figs. 5b and 5d). Apparently, this is one of the mechanisms leading to drag reduction, since the drag coefficient is reduced by around $1.7 \%$ for the single-flap model, by utilizing a single flap at the midpoint of the leading edge (Table 1).

Figures 6 and 7 illustrate evaluation of the flow field for all models, in the wake of Ahmed body on the transverse planes of $x / L=-0.08$ and 0 , which are coincident with the midplane of the e-ISSN: 2148-2683 rear slanted surface and the rear vertical base, respectively. Formation of trailing vortex near the side edge of the slanted surface is delayed in the two- and three-flap models, due to the suction generated by the flaps. It can be deduced that this is another mechanism for reduction in drag, as drag coefficient of the two-flap model is reduced by approximately $1.1 \%$, compared to that of the no-flap model (Table 1).

Skin friction lines with pressure contours on the slanted surface are shown in Fig. 8, where discontinuities in skin friction lines along the leading and side edges of the slanted surface indicate flow separation. For two- and three-flap models, flow near the side edge becomes attached along a longer part of the slanted surface, again due to the suction effect of the flaps (Figs. 8c and 8d). Pressure distribution on the slanted surface indicates that area of regions with relatively higher pressure on the slanted surface increases with number of flaps, and therefore reduction in pressure drag is augmented. No remarkable difference in pressure distribution on the rear vertical base is evident, except for that, a slight increase is observed for the three-flap model near the side edge of the base. The three-flap model with $25^{\circ}$ rear slant angle has the smallest drag coefficient (Table 1), since both mechanisms of drag reduction are exploited. It can be concluded that, although it is in reverse direction, employing small flaps provides an attached flow on the slanted surface, leading to reduced drag.

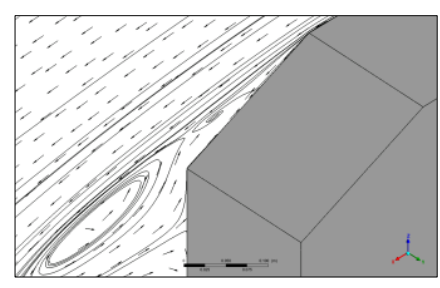

a.

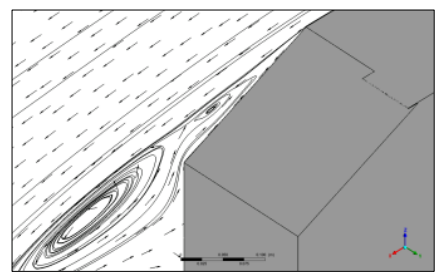

c.

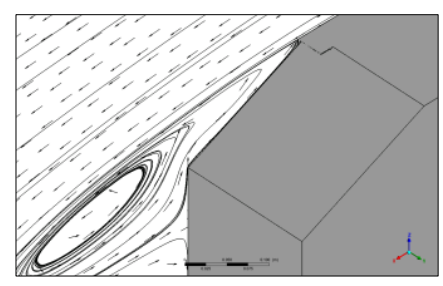

b.

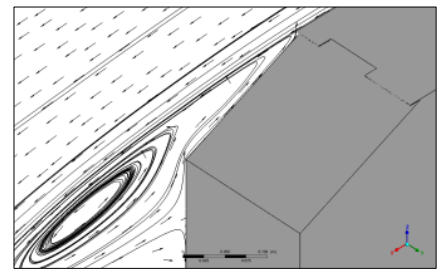

d.
Figure 5. Streamlines and vectors on the symmetry plane $(y / W=$ 0 ) for the a) reference (no-flap), b) single-flap, c) two-flap, and d) three-flap models $\left(25^{\circ}\right.$ rear slant angle $)$ 


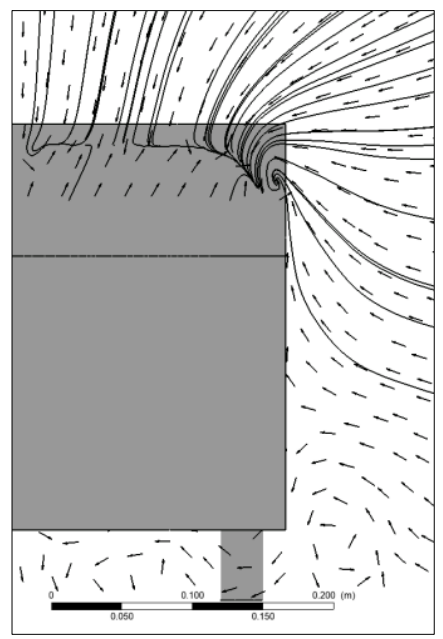

a.

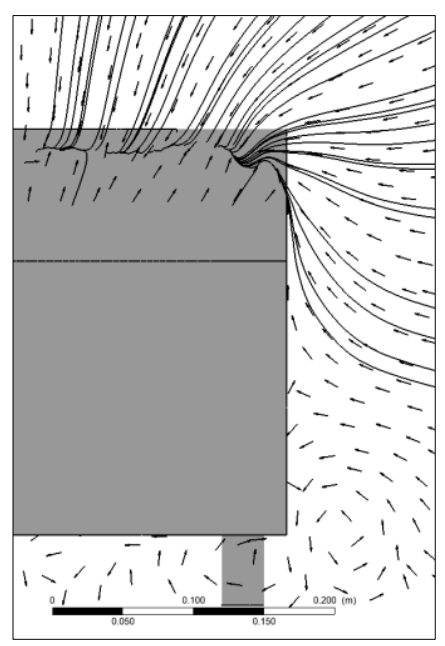

c.

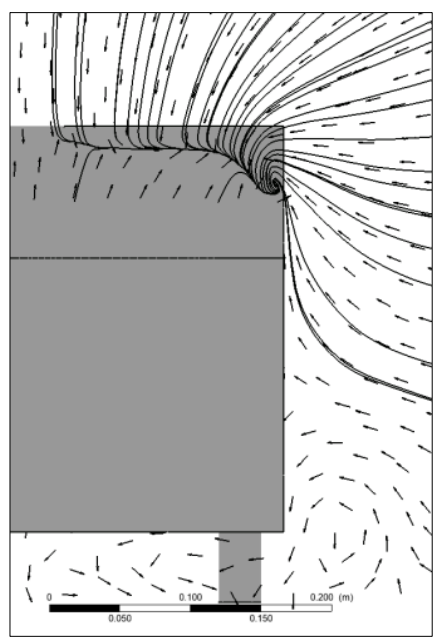

b.

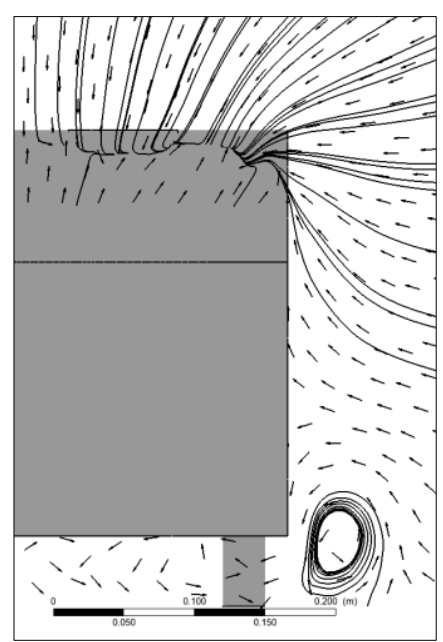

d.

Figure 6. Streamlines and vectors on the plane $x / L=-0.08$ : a) reference (no-flap), b) single-flap, c) two-flap, and d) three-flap models $\left(25^{\circ}\right.$ rear slant angle)
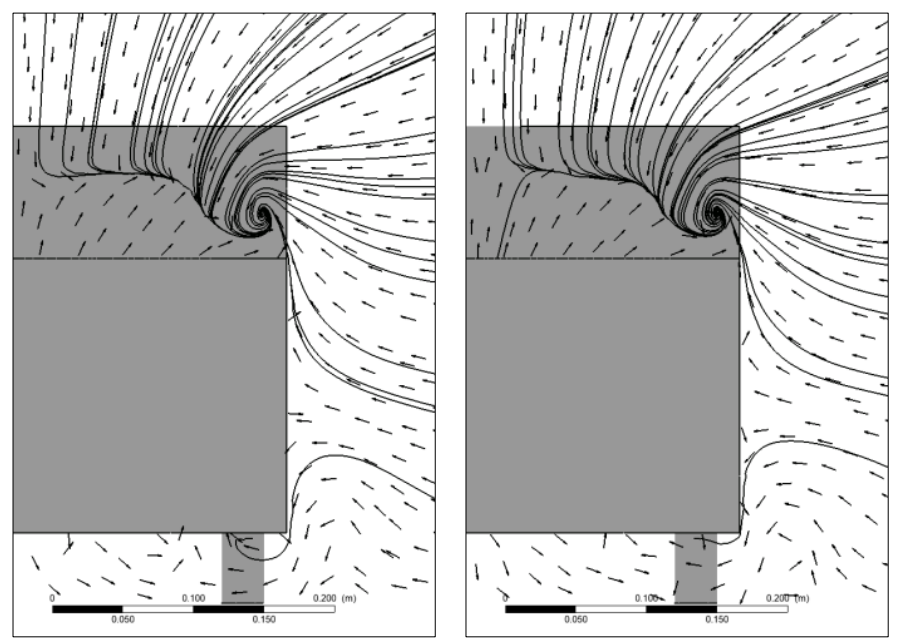
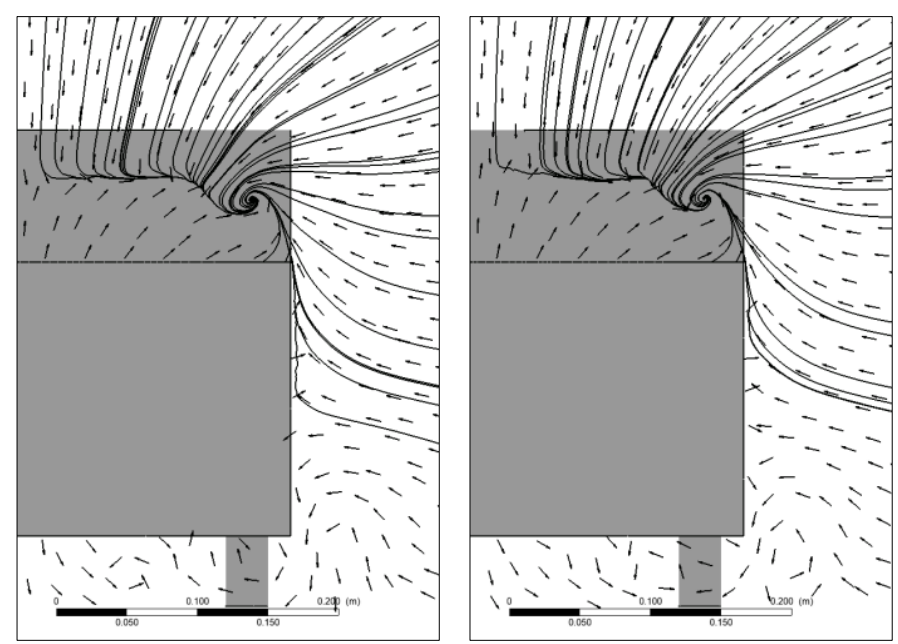

Figure 7. Streamlines and vectors on the plane $x / L=0$ : a) reference (no-flap), b) single-flap, c) two-flap, and d) three-flap models $\left(25^{\circ}\right.$ rear slant angle $)$

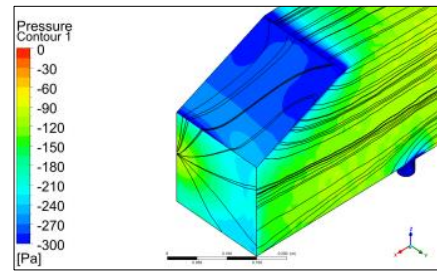

a.

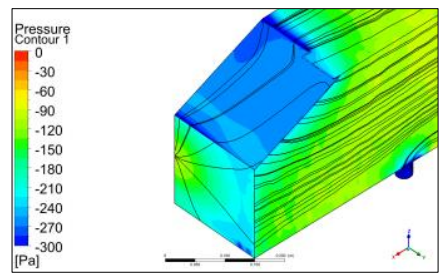

c.

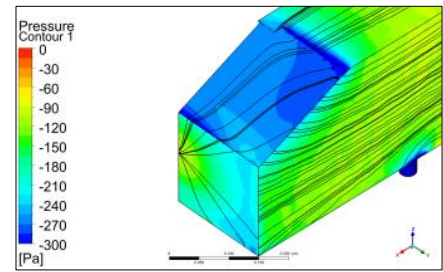

b.

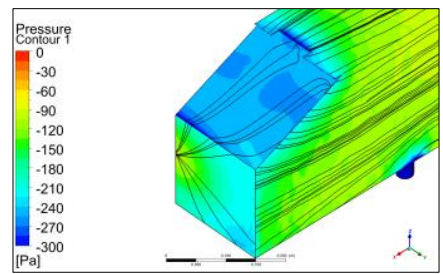

d.
Figure 8. Pressure contours with superimposed skin friction lines over the Ahmed body for the a) reference (no-flap), b) single-flap, c) two-flap, and d) three-flap models $\left(25^{\circ}\right.$ rear slant angle)

As for $35^{\circ}$ rear slant angle, addition of flaps on the leading edge of the slanted surface make no remarkable difference in the flow field; since, unlike the case of $25^{\circ}$ rear slant angle, the reversed flow on the slanted surface is already attached and a secondary vortex is not formed above the slanted surface (Figs. 9 and 10). Pressure distribution over the slanted surface is not affected by the existence of the flaps, except for the region of relatively higher pressure below the flap centered around the symmetry plane (Figs. 11b and 11d). On the other hand, the flaps located at each end of the leading edge leads to a local decrease in pressure on the rear vertical base, while lines of skin friction on the slanted surface are curved towards the side edge (Figs.11c and 11d). This might be the reason for the slight increase in the drag coefficient (Table 1). Apparently, employing small flaps on the leading edge of the slanted surface has a negative effect in terms of drag coefficient for $35^{\circ}$ rear slant angle, since regions of suction is already generated in the reference (no-flap) model along the leading edge (Fig. 11a). Also, the drag coefficient of the threeflap model for $25^{\circ}$ rear slant angle is very close to that of the no- 
flap model for $35^{\circ}$ rear slant angle (Table 1). This can be interpreted as that utilization of small flaps leads Ahmed body with $25^{\circ}$ rear slant angle to approach to that with $35^{\circ}$ rear slant aerodynamically.

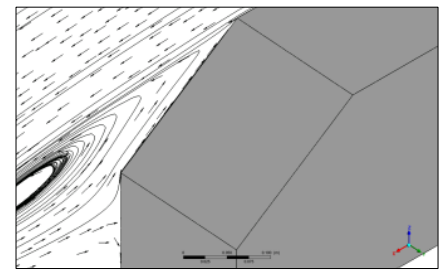

a.

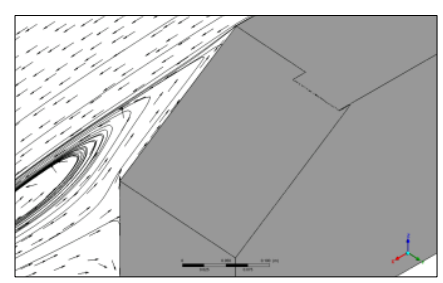

c.

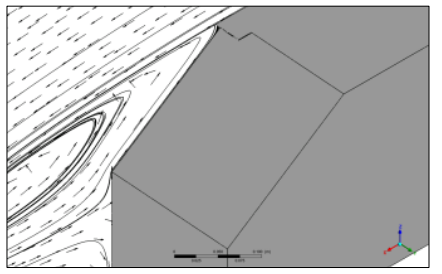

b.

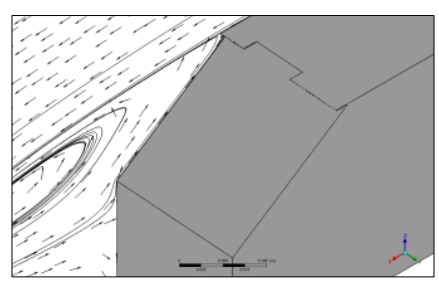

d.
Figure 9. Streamlines and vectors plotted on the symmetry plane $(y / W=0)$ for the a) reference (no-flap), b) single-flap, c) twoflap, and d) three-flap models ( $35^{\circ}$ rear slant angle)

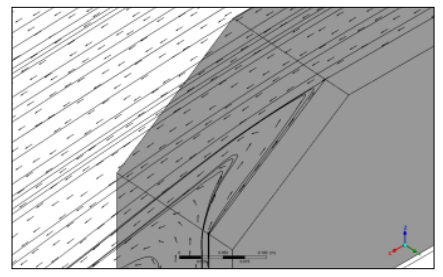

a.

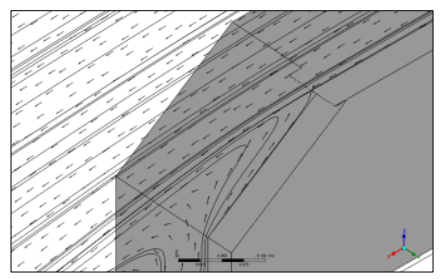

c.

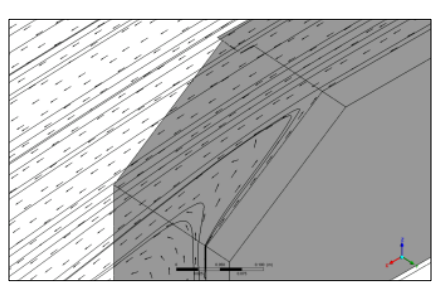

b.

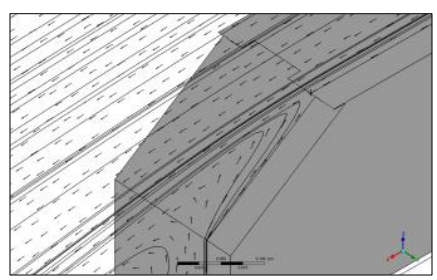

d.
Figure 10. Streamlines and vectors plotted on $y / W=0.4$ plane for the a) reference (no-flap), b) single-flap, c) two-flap, and d) three-flap models $\left(35^{\circ}\right.$ rear slant angle)

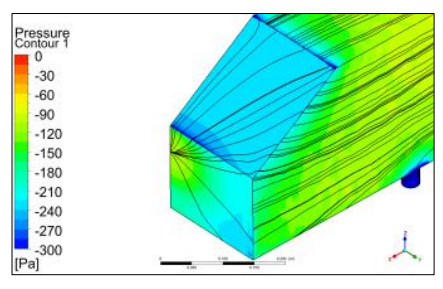

a.

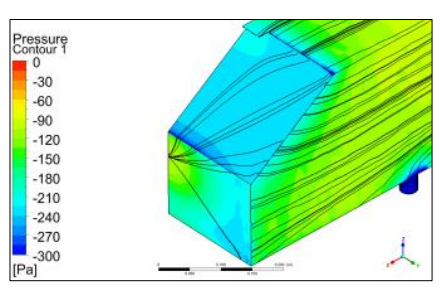

b.

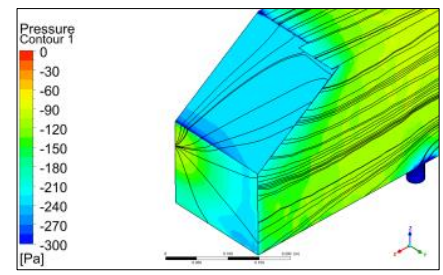

c.

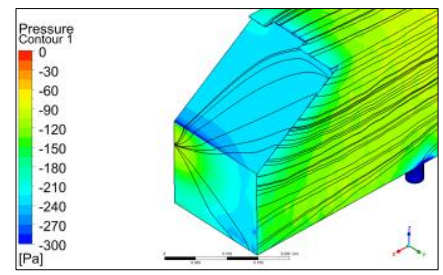

d.
Figure 11. Pressure contours with superimposed skin friction lines over the Ahmed body for the a) reference (no-flap), b) single-flap, c) two-flap, and d) three-flap models $\left(35^{\circ}\right.$ rear slant angle)

\section{Conclusions and Recommendations}

Three-dimensional incompressible steady turbulent air flow around Ahmed body with small flaps attached to the leading edge of the rear slanted surface is investigated numerically. Numerical solutions are obtained for single-flap, two-flap, and three-flap configurations with rear slant angles of both 25 and 35 degrees; and values of drag coefficient, as well as velocity and pressure fields are presented.

Results of the numerical calculations have shown that addition of small flaps reduces the drag coefficient only for $25^{\circ}$ rear slant angle. Accordingly, two distinct mechanisms for drag reduction are observed: i) Elimination of the vortex formed above the slanted surface, and ii) delaying the formation of trailing vortices near the side edges of the rear slanted surface. Maximum relative reduction in the drag coefficient is achieved with the three-flap model for $25^{\circ}$ slant angle by approximately $2.5 \%$, where both mechanisms of drag reduction are exploited simultaneously.

It is also shown that there is no reduction in the drag coefficient of the models with $35^{\circ}$ rear slant angle since the flow on the rear slanted surface is mostly attached. Therefore, the main argument of the passive flow control method considered herein is not available for this case. Mounting flaps even has aerodynamically negative effect for two- and three-flap models with $35^{\circ}$ rear slant angle, by causing local regions of relatively lower pressure to be generated on the rear vertical base of the body. Regarding the values of the drag coefficients, mounting flaps to the leading edge of the rear slanted surface makes the model with $25^{\circ}$ rear slant angle aerodynamically approach to that with $35^{\circ}$ rear slant angle.

Additional calculations for more than three flaps, as well as a single flap covering the whole leading edge of the rear slanted surface would be useful to have a deeper knowledge on the phenomena. Also, parameters that might be of interest in future studies are dimensions and other geometrical properties of the flaps.

\section{References}

[1] Byrne, C. E. I. (1999). Aerodynamics of Road Vehicles, 4th edition. Edited by WH. Hucho. SAE International, Warrendale, PA, USA. Materials Park, OH 44073-0002, USA 1998. 918 pp. Illustrated. 78. The Aeronautical Journal, 103(1026), 398-398.

[2] McCallen, R., Salari, K., Ortega, J., Castellucci, P., Browand, F., Hammache, M., ... \& Pointer, D. (2004, June). DOE's 
effort to reduce truck aerodynamic drag-joint experiments and computations lead to smart design. In 34th AIAA Fluid Dynamics Conference and Exhibit (p. 2249).

[3] Ahmed, S. R., Ramm, G., \& Faltin, G. (1984). Some salient features of the time-averaged ground vehicle wake. SAE Transactions, 473-503.

[4] Siddiqui, N. A., \& Chaab, M. A. (2020). A Simple Passive Device for the Drag Reduction of an Ahmed Body. Journal of Applied Fluid Mechanics, 14(1).

[5] Delassaux, F., Mortazavi, I., Itam, E., Herbert, V., \& Ribes, C. (2021). Sensitivity analysis of hybrid methods for the flow around the ahmed body with application to passive control with rounded edges. Computers \& Fluids, 214, 104757.

[6] Hanfeng, W., Yu, Z., Chao, Z., \& Xuhui, H. (2016). Aerodynamic drag reduction of an Ahmed body based on deflectors. Journal of Wind Engineering and Industrial Aerodynamics, 148, 34-44.

[7] McNally, J. W., Alvi, F. S., Mazellier, N., \& Kourta, A. (2015). Active flow control on an ahmed body-an experimental study. In 53rd AIAA aerospace sciences meeting (p. 0825).

[8] Tsai, C. H., Fu, L. M., Tai, C. H., Huang, Y. L., \& Leong, J. C. (2009). Computational aero-acoustic analysis of a passenger car with a rear spoiler. Applied Mathematical Modelling, 33(9), 3661-3673.

[9] Kurec, K., Remer, M., \& Piechna, J. (2019). The influence of different aerodynamic setups on enhancing a sports car's braking. International Journal of Mechanical Sciences, 164, 105140.

[10]Han, M. W., Rodrigue, H., Cho, S., Song, S. H., Wang, W., Chu, W. S., \& Ahn, S. H. (2016). Woven type smart soft composite for soft morphing car spoiler. Composites Part B: Engineering, 86, 285-298.

[11]Yuan, C. S., Mansor, S., \& Abdullah, M. A. (2017). Effect of spoiler angle on the aerodynamic performance of hatchback model. Int. J. Appl. Eng. Res, 12(22), 12927-12933.

[12]Altaf, A., Omar, A. A., \& Asrar, W. (2014). Passive drag reduction of square back road vehicles. Journal of Wind Engineering and Industrial Aerodynamics, 134, 30-43.

[13]Huminic, A., Huminic, G., \& Soica, A. (2012). Study of aerodynamics for a simplified car model with the underbody shaped as a Venturi nozzle. International Journal of Vehicle Design, 58(1), 15-32.

[14]Mohammadikalakoo, B., Schito, P., \& Mani, M. (2020). Passive flow control on Ahmed body by rear linking tunnels. Journal of Wind Engineering and Industrial Aerodynamics, 205, 104330.

[15]Buscariolo, F. F., Assi, G. R., \& Sherwin, S. J. (2021). Computational study on an Ahmed Body equipped with simplified underbody diffuser. Journal of Wind Engineering and Industrial Aerodynamics, 209, 104411.

[16]Kashyap, V., Arora, B. B., Bhattacharjee, S., \& Mittal, P. (2019). Aerodynamic Effect of Aspect Ratio of Spherical Depressions on the Bonnet of Hatchback Cars (No. 2019-015096). SAE Technical Paper.

[17]Shadmani, S., Mojtaba, M., Mojtaba Mousavi Nainiyan, S., Mirzaei, M., Ghasemiasl, R., \& Pouryoussefi, S. G. (2018). Experimental investigation of flow control over an Ahmed body using DBD plasma actuator. Journal of Applied Fluid Mechanics, 11(5), 1267-1276.

[18]Bayındırlı, C., Çelik, M., \& Demiralp, M. (2018). Bir otobüs modeli etrafındaki akış yapısının CFD yöntemi ile incelenmesi ve sürükleme kuvvetinin pasif akış kontrol yöntemi ile iyileştirilmesi. Politeknik Dergisi, 21(4), 785795.

[19]Zafer, B., \& Haskaraman, F. (2017). Önden ve yanal rüzgâr şartı altında Ahmed cisminin sayısal incelenmesi. Journal of the Faculty of Engineering \& Architecture of Gazi University, 32(1).

[20]Bayındırlı, C., \& Çelik, M. Bir Taşıta Etki Eden Aerodinamik Direnç Kuvvetinin Bagaj Üstü Spoiler ile İyileştirilmesi. Afyon Kocatepe Üniversitesi Fen ve Mühendislik Bilimleri Dergisi, 19(2), 470-479.

[21]Beaudoin, J. F., \& Aider, J. L. (2008). Drag and lift reduction of a 3D bluff body using flaps. Experiments in fluids, 44(4), 491-501.

[22]Le Good, G. M., \& Garry, K. P. (2004). On the use of reference models in automotive aerodynamics.

[23]Cengel, Y. A. (2010). Fluid mechanics. Tata McGraw-Hill Education. 